Supplement of Atmos. Chem. Phys. Discuss., 15, 35485-35521, 2015

http://www.atmos-chem-phys-discuss.net/15/35485/2015/

doi:10.5194/acpd-15-35485-2015-supplement

(C) Author(s) 2015. CC Attribution 3.0 License.

(c) (i)

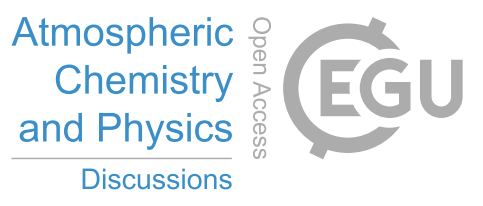

Supplement of

\title{
Evidence for ambient dark aqueous SOA formation in the Po Valley, Italy
}

A. P. Sullivan et al.

Correspondence to: A. P. Sullivan (sullivan@atmos.colostate.edu)

The copyright of individual parts of the supplement might differ from the CC-BY 3.0 licence. 


\section{AMS Organic Aerosol Source Apportionment}

Source apportionment analysis on the high resolution organic aerosol (OA) mass spectra provided by the AMS was made using the Multilinear Engine algorithm (ME-2) developed by Paatero [1999] and the interface Solution Finder (SoFi 4.9) [Canonaco et al., 2013]. Prior to analysis, the organic matrix was prepared according to the recommendations of Ulbrich et al. [2009]. First, isotope ions were removed and a minimum counting error was applied. Fragments with a signal-to-noise ratio (SNR) below 0.2 were down-weighted by a factor of 10 and fragments with a SNR between 0.2 and 2 were down-weighted by a factor of 2 . Finally, the fragments related to ion $\mathrm{CO}_{2}{ }^{+}$were also down-weighted since they are calculated as a constant fraction of the ion $\mathrm{CO}_{2}{ }^{+}$[Allan et al., 2004]. Elemental analysis on the mass spectra of the identified factors was performed using the Analytic Procedure for Elemental Separation (APES vers. 1.06) based on Aiken et al. [2007, 2008] and including the improved estimation from Canagaratna et al. [2015].

For the first attempt, a non-constrained approach was investigated using a factor number ranging from 1 to 6 and applying 10 seeds (Figure S1). The best solution was obtained for the 4factors solution (Figure S2) including 3 different oxygenated OA (OOA-a, OOA-b and OOA-c) and a mixed-sources factor (mix-OA). The mix-OA factor contributes to $16 \%$ of the total OA and it has a mass spectrum with ions typically associated with hydrocarbon-like OA and shows the lowest $\mathrm{O} / \mathrm{C}$ (oxygen/carbon) ratio (0.28) compared to the other factors. Although, it indicates that this factor can be related to primary OA, its elemental ratios are higher than reported Hydrocarbon-like OA (HOA) factors [Canagaratna et al., 2015]. This factor also has a large contribution of oxygenated fragments at $\mathrm{m} / \mathrm{z} 43\left(\mathrm{CHO}^{+}\right)$and $44\left(\mathrm{CO}_{2}^{+}\right)$compared to previously reported HOA factors. Regarding its time variation, this factor correlates relatively well with gas-phase primary emissions tracers (e.g., benzene $(\mathrm{r}=0.35)$, toluene $(\mathrm{r}=0.48)$ ) and particulate black carbon (BC, $\mathrm{r}=0.49$ ) as well as with semi-volatile inorganic compounds (e.g., nitrate $(\mathrm{r}=0.57))$. Therefore, considering the mass spectrum and time series particularities, this factor was identified to represent a mixture of Hydrocarbon-like OA (HOA) and semi-volatile OA (SVOOA). The three OOA factors have quite similar mass spectra, but they present clear distinct time trends. Therefore, they are considered as separate factors and identified as follows:

- OOA-a (10\% of total OA) appears to be specific to a certain time period of the campaign characterized by high temperature, a high pressure system, and stagnant air masses. Therefore, this OOA-a factor can be related to an accumulation of aged particles on the regional background. The OOA-a mass spectrum is dominated by oxygenated ions and shows the highest $\mathrm{O} / \mathrm{C}$ ratio (1.02) in agreement with aged OA.

- OOA-b (30\% of total OA) is the least oxygenated OOA factors $(\mathrm{O} / \mathrm{C}=0.55)$. It also correlates well with sulfate $(r=0.58)$, but also with methanesulfonic acid (MSA, $r=0.60)$. Therefore, this suggested that OOA-b might be related to marine OA rather than continental OA. This is in agreement with previous measurements made at the same location by Saarikoski et al. [2012], who reported a factor with a source originating from the Mediterranean Sea.

- OOA-c (44\% of total OA) correlates with particulate sulfate ( $r=0.55)$ but not with MSA, opposite to OOA-b, and therefore can be linked to more "continental” SOA formation. 
Increasing the number of factors did not provide a significant change on the mix-OA factor as illustrated in Figure S3 but rather a change in the split of the different OOA factors. Therefore, as a second attempt, the source apportionment was performed in a semi-constrained mode in order to dissociate primary OA from semi-volatile OA more clearly. The principal primary OA source expected is the HOA factor. In contrary to Saarikoski et al. [2012] who reported the contribution of a Biomass Burning OA (BBOA) factor in the spring season, here no BBOA is expected since the contribution of the fragment $\mathrm{m} / \mathrm{z} 60$ (a tracer for BBOA) to total OA was systematically below the background level of $0.3 \%$ defined by Cubison et al. [2011]. Consequently, a reference HOA mass spectrum corresponding to an average of 2 HOA factors previously identified in this area (M. Rinaldi, personal communication) was used as a priori information to partially constrain the model.

For this approach, the number of factors was varied from 5 to 7 since at least 5 factors are expected based on previous AMS measurements in the Po Valley (HOA and 4 types of OOA). In order to test the sensitivity of the results, the difference in the degree of variation for the various fragments for the output HOA factor to the input reference mass spectra (the so-called a-value) was investigated for a-values ranging from 0.05 (i.e., extremely constrained run where fragments of the resulting HOA factor can only vary from $5 \%$ compared to the reference HOA) to 0.5 (50\% variation). The contribution of the HOA to the total OA was extremely stable over the investigated a-value range indicating that identification of the HOA factor is quite robust (Figure S4). The 5-factors solution (with an a-value of 0.1) was considered as the final solution (Figure S5). This solution corresponds to better discrimination between HOA and the semi-volatile OA (referred in the following as OOA-1), while the 3 others OOA factors correspond to the previously identified ones in the non-constrained model and here are referred to as OOA-2 (12\% of OA), OOA-3 (28\% of OA), and OOA-4 (45\% of OA) in order to avoid confusion when referring to the first (unconstrained) analysis (Figures S6 and S7). Increasing the number of factors to 6 or 7 solely leads to a further splitting of the OOA factors without a clear identification.

The HOA factor ( $4 \%$ of OA) now better follows the time trend of benzene ( $\mathrm{r}=0.58)$, while no real improvement of the correlation with $\mathrm{BC}(\mathrm{r}=0.50)$ and toluene $(\mathrm{r}=0.49)$ can be reported. However, the semi-volatile OOA- 1 is now better correlated with nitrate $(\mathrm{r}=0.74)$ than HOA ( $\mathrm{r}=0.36)$ confirming the presence of these two factors in the previously identified mix-OA.

Although the OOA-1 factor (12\% of total OA) is related to semi-volatile OA, its mass spectrum appears to be more oxygenated (higher contribution of the $\mathrm{CO}_{2}{ }^{+}$fragment compared to the $\left.\mathrm{CHO}^{+}\right)$than classical SV-OOA $\left(\mathrm{CHO}^{+}>\mathrm{CO}_{2}{ }^{+}\right)$. However, this is quite similar to the previously reported semi-volatile OOA measured at SPC by Saarikoski et al. [2012].

Although contributions of the 3 others OOA factors (OOA-2, OOA-3, and OOA-4) to the total $\mathrm{OA}$ are quite similar to the contribution of their corresponding factors in the nonconstrained mode (12\%, $28 \%$ and $45 \%$, respectively), some small differences can be reported either in terms of their mass spectra (and consequently their elemental ratios) or their time trends. These differences can be explained by a small contribution of the non-constrained OOA factors (i.e., OOA-a, OOA-b, and OOA-c) to OOA-1. The most stable factor is OOA-2 which correlates quite well with the previously identified OOA-a, even if the final factor has a lower oxidation state. Although OOA-2 contributed to $12 \%$ over the entire time period, during its prevalent period it accounted for up to more than half of the OA. 


\section{References}

Aiken, A. C., P.F. DeCarlo, and J.L. Jimenez, Elemental analysis of organic species with electron ionization high-resolution mass spectrometry, Anal. Chem., 79, 8350-8358, doi:10.1021/ac071150w, 2007.

Aiken, A. C., P.F. Decarlo, J.H. Kroll, D.R. Worsnop, J.A. Huffman, K.S. Docherty, I.M. Ulbrich, C. Mohr, J.R. Kimmel, D. Sueper, Y. Sun, Q. Zhang, A. Trimborn, M. Northway, P.J. Ziemann, M.R. Canagaratna, T.B. Onasch, M.R. Alfarra, A.S.H. Prévôt, J. Dommen, J. Duplissy, A. Metzger, U. Baltensperger, and J.L. Jimenez, O/C and $\mathrm{OM} / \mathrm{OC}$ ratios of primary, secondary, and ambient organic aerosols with high-resolution time-of-flight aerosol mass spectrometry, Environ. Sci. Technol., 42, 4478-4485, doi:10.1021/es703009q, 2008.

Allan, J., A.E. Delia, H. Coe, K.N. Bower, R.M. Alfarra, J.L. Jimenez, A.M. Middlebrook, F. Drewnick, T.B. Onasch, M.R. Canagaratna, J.T. Jayne, and D.R. Worsnop, A generalised method for the extraction of chemically resolved mass spectra from Aerodyne aerosol mass spectrometer data, J. Aerosol Sci., 35, 909 - 922, doi:10.1016/j.jaerosci.2004.02.007, 2004.

Canagaratna, M. R., J.L. Jimenez, J.H. Kroll, Q. Chen, S.H. Kessler, P. Massoli, L.H. Ruiz, E. Fortner, L.R. Williams, K.R. Wilson, J.D. Surratt, N.M. Donahue, J.T. Jayne, and D.R. Worsnop, Elemental ratio measurements of organic compounds using aerosol mass spectrometry: characterization, improved calibration, and implications, Atmos. Chem. Phys., 15, 253-272, doi:10.5194/acp-15-253-2015, 2015.

Canonaco, F., M. Crippa, J.G. Slowik, A.S.H. Prévôt, and U. Baltensperger, SoFi, an IGORbased interface for the efficient use of the generalized multilinear engine (ME-2) for the source apportionment: ME-2 application to aerosol mass spectrometer data, Atmos. Meas. Tech., 6, 3649-3661, doi:10.5194/amt-6-3649-2013, 2013.

Cubison, M. J., A.M. Ortega, P.L. Hayes, D.K. Farmer, D.E. Day, M.J. Lechner, W.H. Brune, E.C. Apel, G.S. Diskin, J.A. Fisher, H.E. Fuelberg, A. Hecobian, D.J. Knapp, T. Mikoviny, D.D. Riemer, G. Sachse, W. Session, R.J. Weber, A.J. Weinheimer, A. Wisthaler, and J.L. Jimenez, Effects of aging on organic aerosol from open biomass burning smoke in aircraft and laboratory studies, Atmos. Chem. Phys., 11, 12049-12064, 2011.

Paatero, P., The multilinear engine - A table-driven, least squares program for solving multilinear problems, including the n-way parallel factor analysis model, Journal of Computational and Graphical Statistics, 8, 854-888, doi:10.2307/1390831, 1999.

Saarikoski, S., S. Carbone, S. Decesari, L. Giulianelli, F. Angelini, M. Canagaratna, N.L. Ng, A. Trimborn, M.C. Facchini, S. Fuzzi, R. Hillamo, and D. Worsnop, Chemical characterization of springtime submicrometer aerosol in Po Valley, Italy, Atmos. Chem. Phys., 12, 8401-8421, doi:10.5194/acp-12-8401-2012, 2012. 
184 Ulbrich, I. M., M.R. Canagaratna, Q. Zhang, D.R. Worsnop, and J.L. Jimenez, Interpretation of 185 organic components from Positive Matrix Factorization of aerosol mass spectrometric 186 187 
Figure Captions

231 Figure S1. Evolution of the $\mathrm{Q} / \mathrm{Q}_{\exp }$ ratio (top) and factor contribution (bottom) over the investigated factor range for the non-constrained model.

Figure S2. Time series (top) and mass spectra colored by fragments family (bottom) for the non-constrained 4-factors solution.

Figure S3. Evolution of the mix-OA factor time series (top) and mass spectra (bottom) for different factor solutions (from 3 to 6). Numbers in parentheses on the bottom plots (following the number of the factor solution) correspond to the slope of the regression line compare to the selected 4-factors solution.

Figure S4. Evolution of the $\mathrm{Q} / \mathrm{Q}_{\exp }$ ratio (top) and factor contribution (bottom) over the

Figure S5. Overview of the partially-constrained factor solution including (a) time series of the factors and corresponding tracers, (b) mass fraction of the different factors to the total OA, and (c) mass spectra of the factors colored by fragment family.

Figure S6. Comparison between the time trends of the factors identified for the non-constrained (y-axis) and the ones identified for the partially-constrained (x-axis) analysis.

Figure S7. Comparison between the mass spectra of the factors identified for the nonconstrained (y-axis) and the ones identified for the partially-constrained (x-axis) analysis. 


\section{Figure S1}
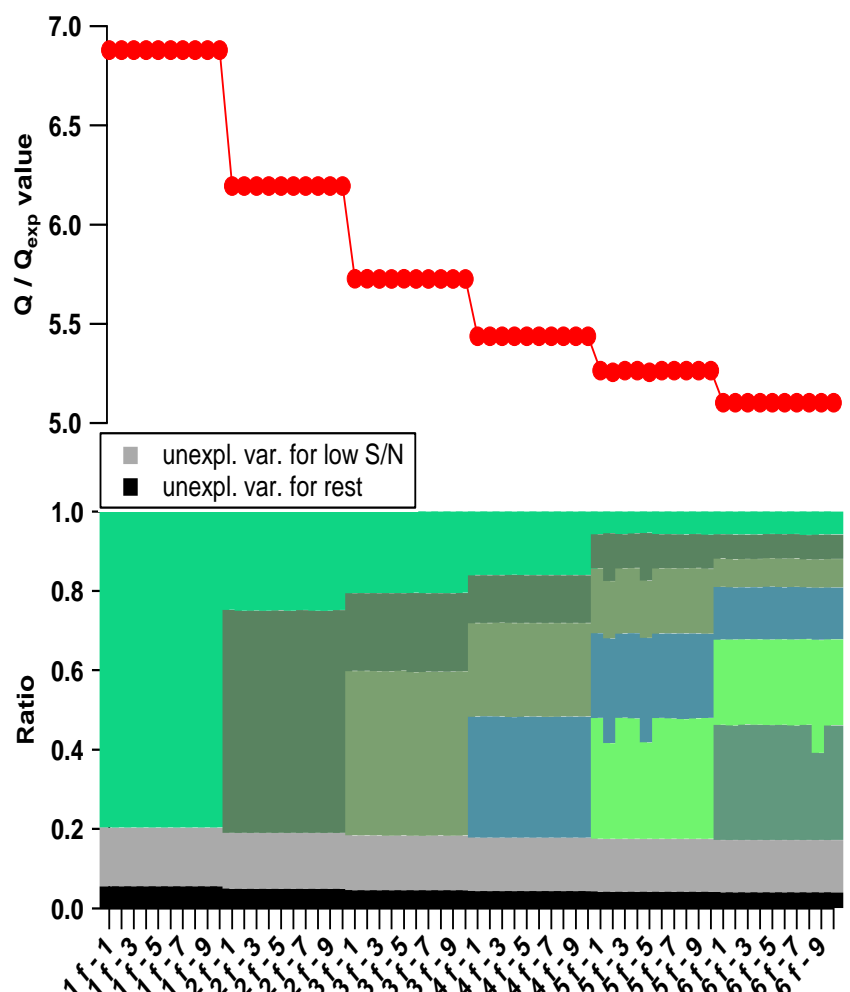

seed 
Figure S2
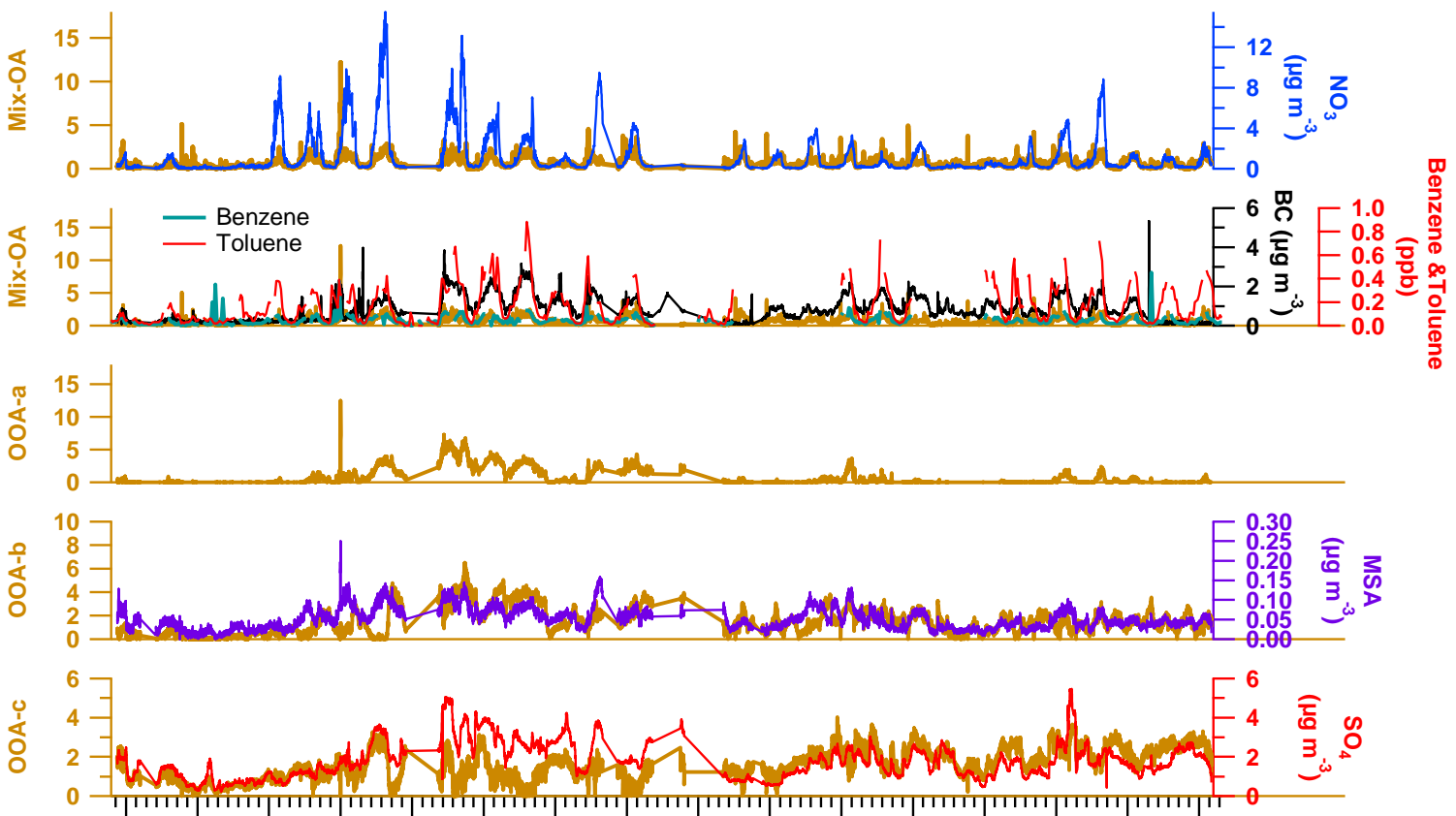

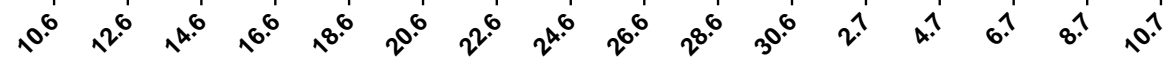

date and time
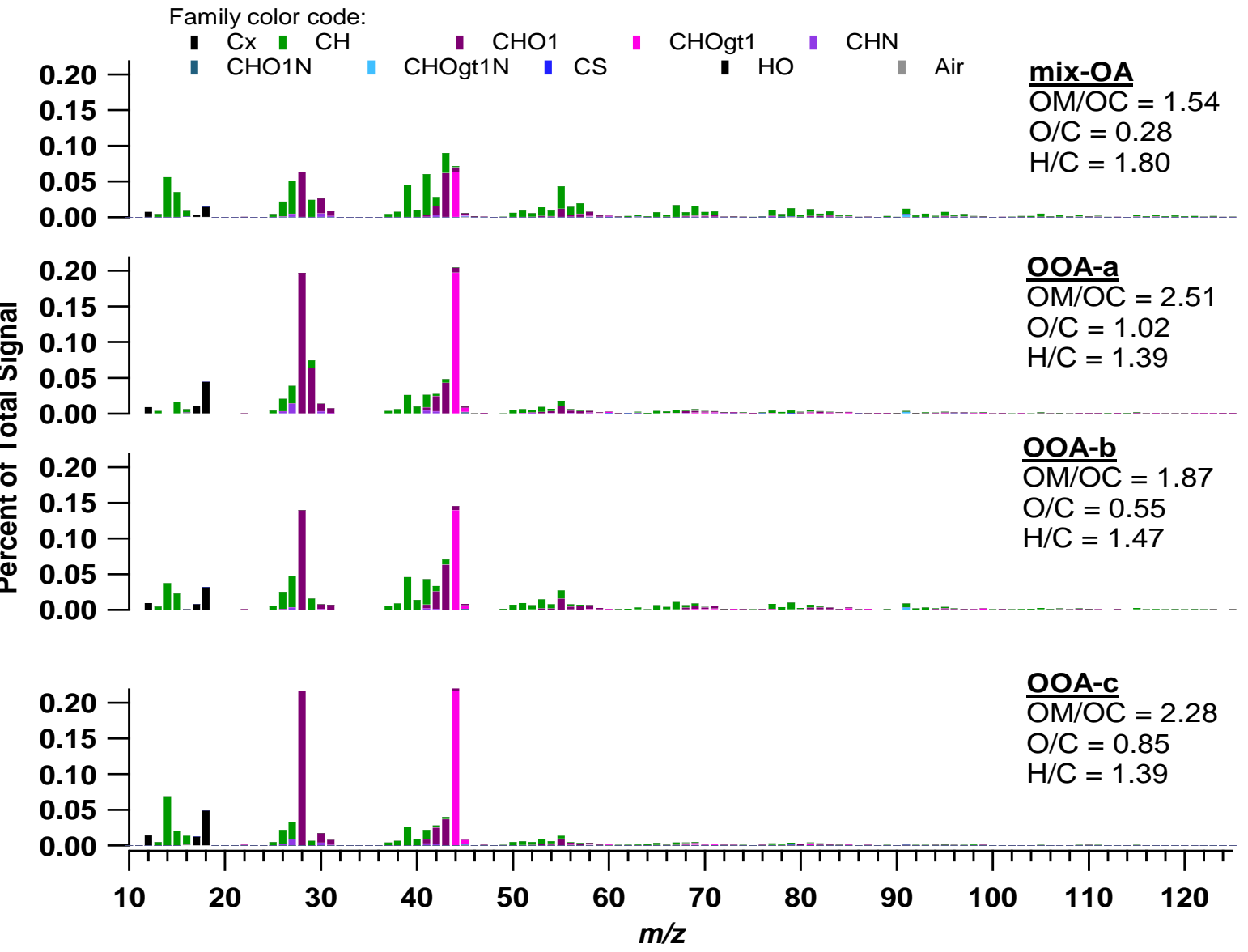


\section{Figure S3}
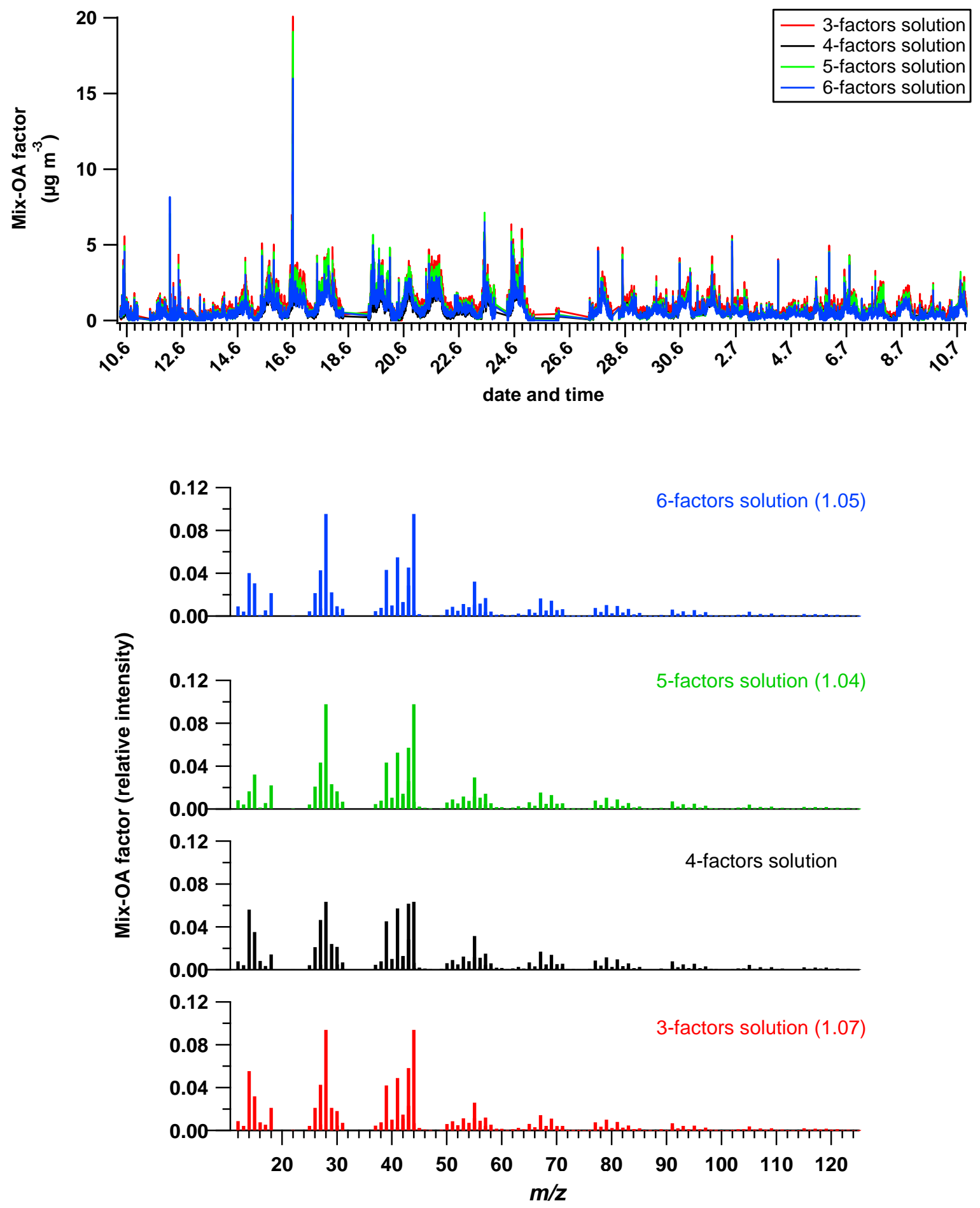
Figure S4
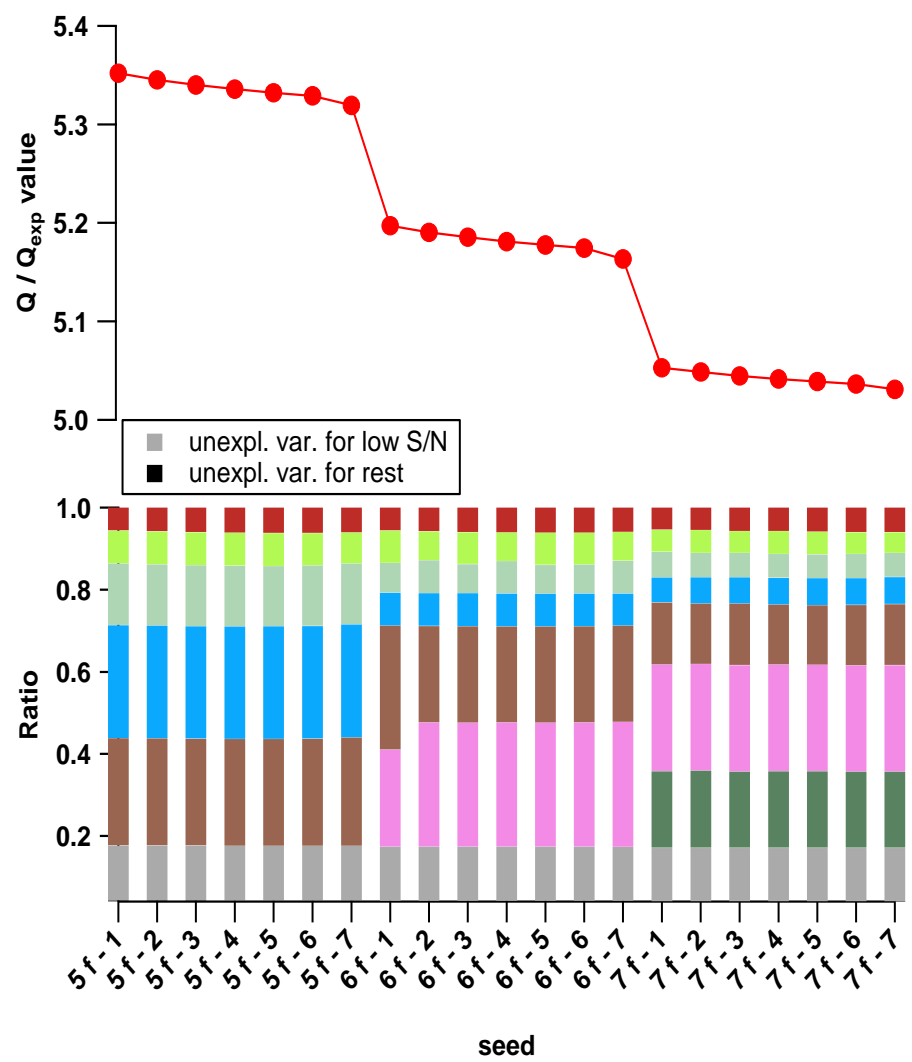


\section{Figure S5}

(a)
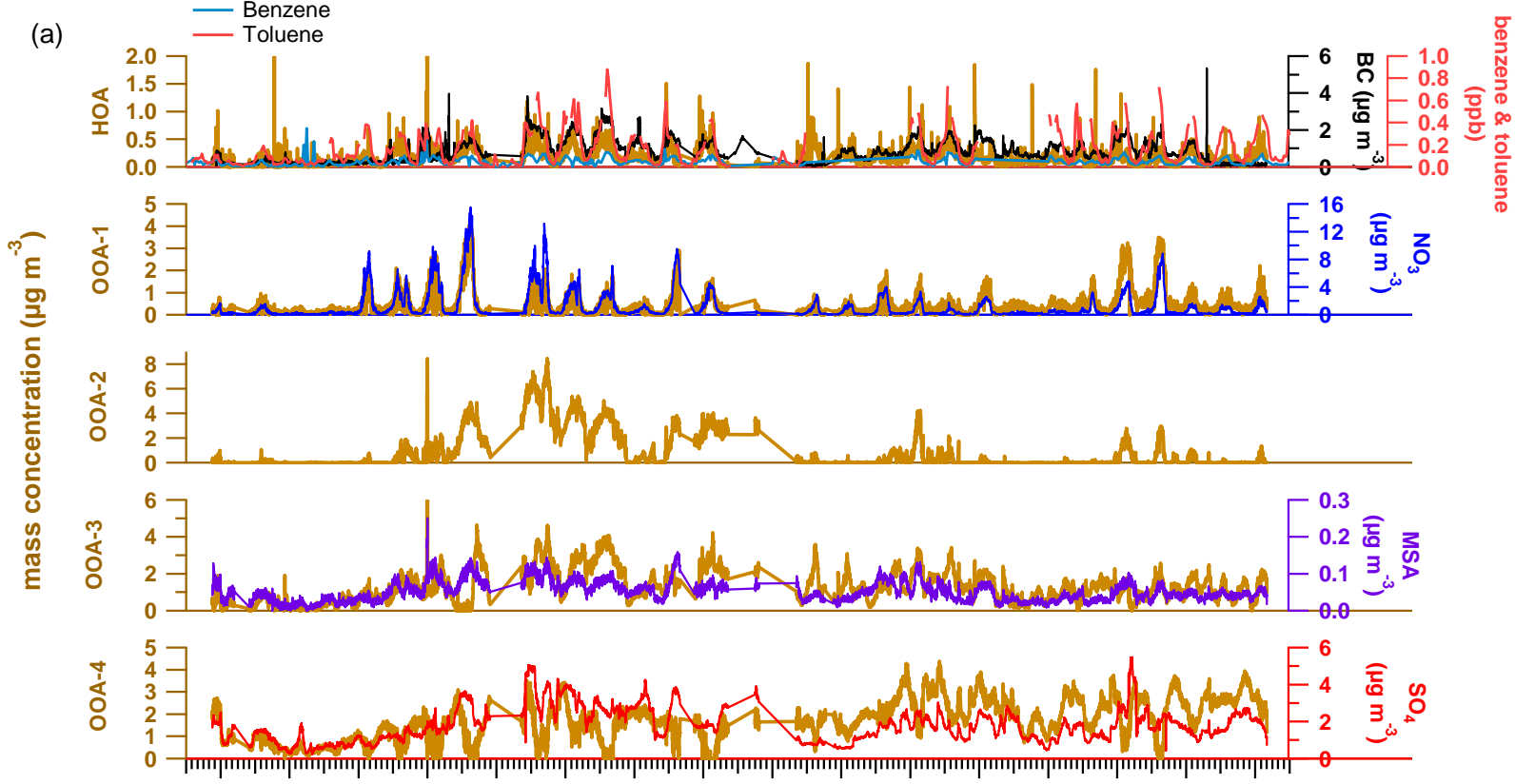

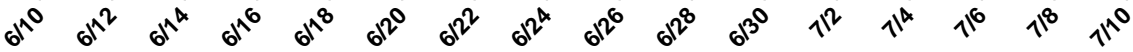

date and time

(b)

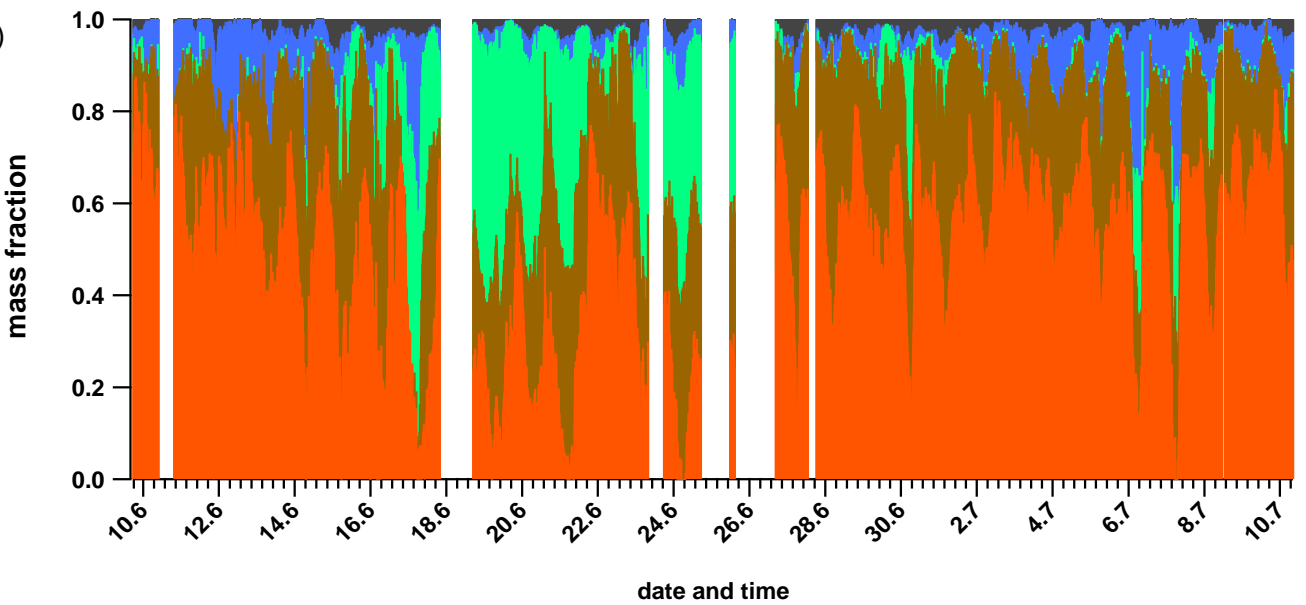

I HOA

OOA-1

OOA-3

OOA-4

date and time 


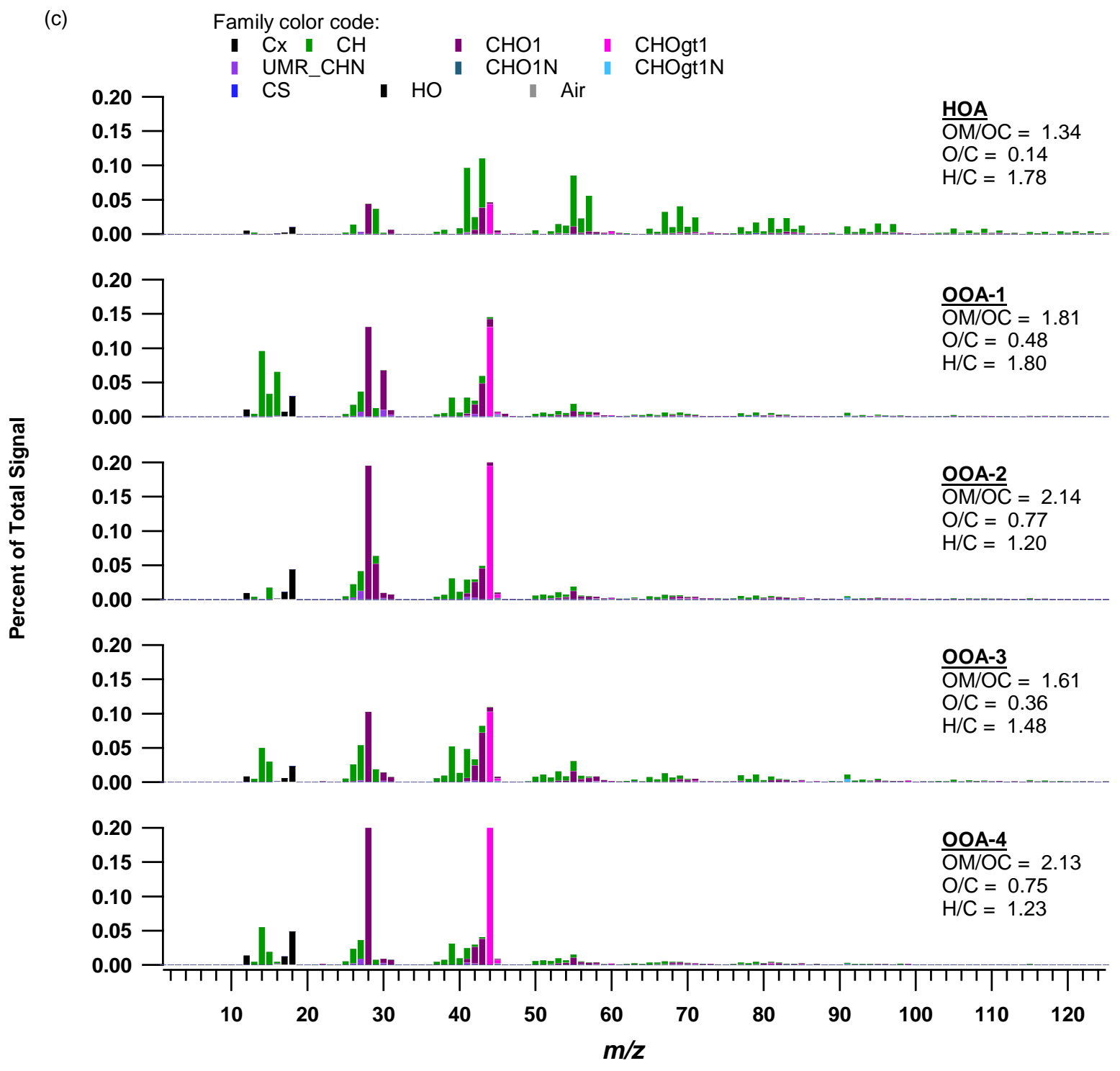


Figure S6
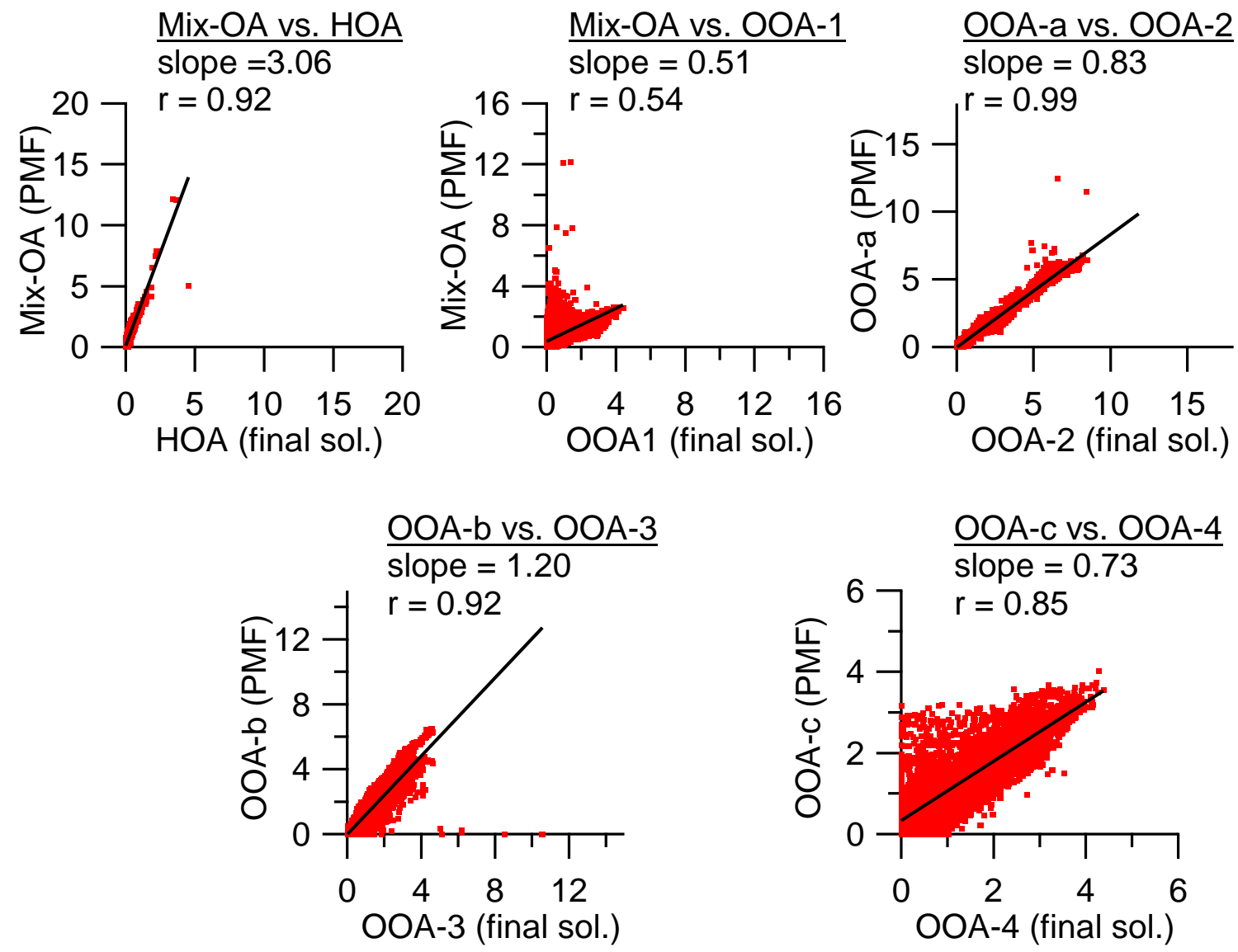
Figure S7
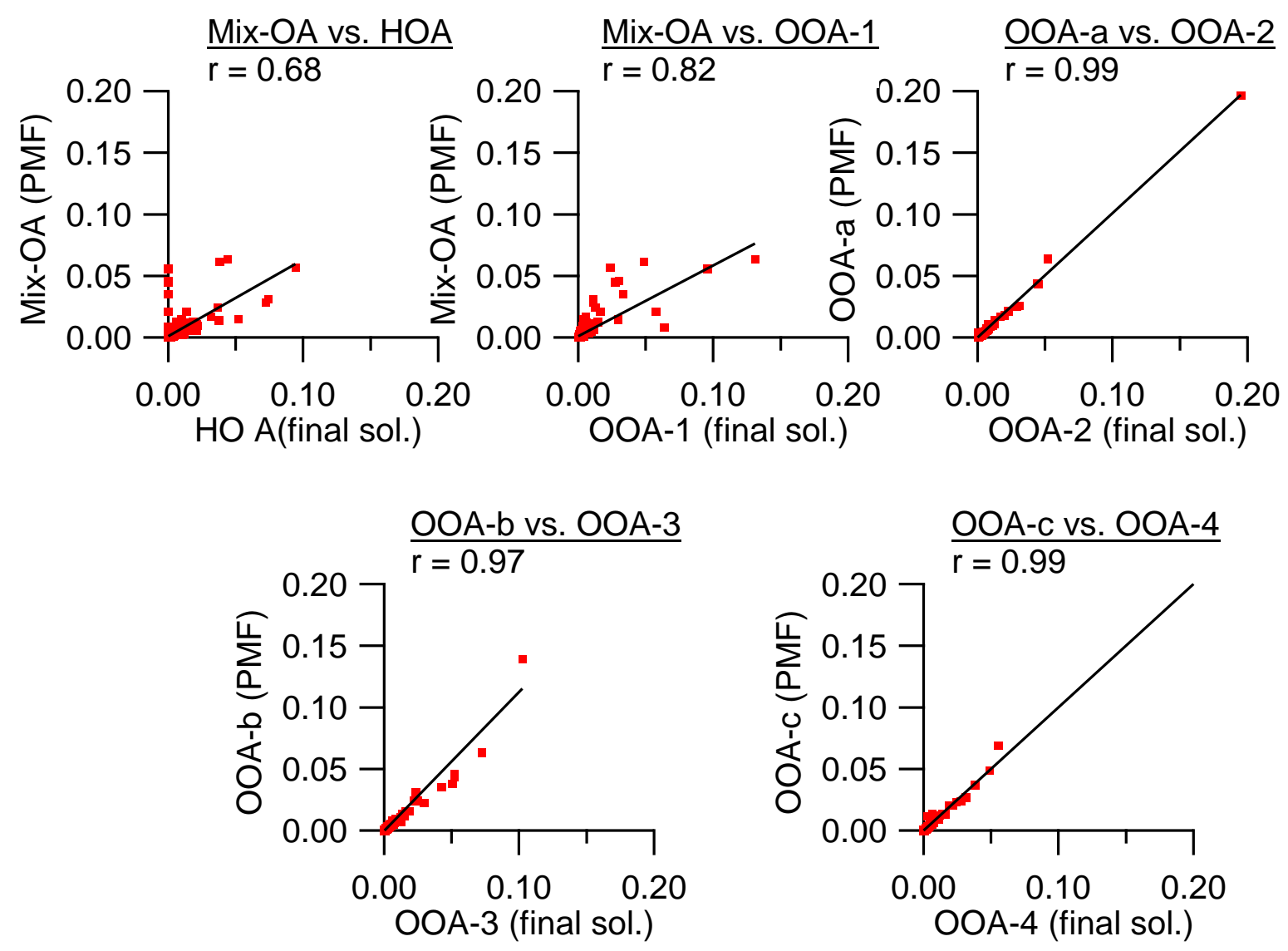